\title{
Clinical efficacy and quality of life after transrectal natural orifice specimen extraction for the treatment of middle and upper rectal cancer
}

\author{
Zhe Zhu ${ }^{1 \#}$, Kai-Jing Wang ${ }^{1 \#}$, Guy R. Orangio ${ }^{2}$, Jun-Yi Han ${ }^{1}$, Bing Lu ${ }^{1}$, Zhu-Qing Zhou ${ }^{1}$, Wei Gao ${ }^{1}$, \\ Chuan-Gang $\mathrm{Fu}^{1}$
}

${ }^{1}$ Department of Colorectal Surgery, Shanghai East Hospital, Tongji University School of Medicine, Shanghai 200120, China; ${ }^{2}$ Department of Surgery, Louisiana State University, New Orleans, LA, USA

Contributions: (I) Conception and design: KJ Wang, Z Zhu, ZQ Zhou, CG Fu; (II) Administrative support: W Gao, CG Fu; (III) Provision of study materials or patients: All authors; (IV) Collection and assembly of data: All authors; (V) Data analysis and interpretation: KJ Wang, Z Zhu; (VI) Manuscript writing: All authors; (VII) Final approval of manuscript: All authors.

\#These authors contributed equally to this work.

Correspondence to: Chuan-Gang Fu; Wei Gao. Department of Colorectal Surgery, Shanghai East Hospital, Tongji University School of Medicine, Shanghai 200120, China. Email: fugang416@163.com; yoursgaowei@163.com.

Background: Laparoscopic anterior resection with natural orifice specimen extraction (NOSE) avoids extra abdominal extraction incision during colorectal surgery. Some surgeons realized the benefits of NOSE on clinical efficacy. We compared the clinical efficacy of laparoscopic NOSE, laparoscopic non-NOSE and open surgery (OS) for short-term recovery and quality of life (QoL).

Methods: A single randomized controlled trial of NOSE for middle and upper rectal cancer between April 2014 and February 2018. Preoperative and postoperative clinical variables were analyzed and compared between the groups. Preoperative and 6 months postoperative QoL was assessed with the SF-36 QoL questionnaire.

Results: A total of 378 patients were enrolled, 334 patients randomly divided into NOSE group (n=104), non-NOSE group $(n=119)$, OS group $(n=111)$. The NOSE group was superior to the other two groups on the QoL after surgery. The NOSE group had the lowest postoperative VAS score between three groups. The postoperative time for bowel function recovery and the length of hospital stay was statistically significantly different among the three groups, with the NOSE group having the shortest time. The incidence of postoperative complications was lower in the NOSE group $(12 / 104,11.5 \%)$ than in the non-NOSE group (20/119, 16.8\%), the difference was statistically significant. The Kaplan-Meier (K-M) survival curve showed no statistically significant difference in the disease-free survival (DFS) rate between the three groups.

Conclusions: Comparing NOSE to non-NOSE and OS, the NOSE had significantly better functional recovery and better QoL. The NOSE group had a significant lower surgical complication rate than the nonNOSE group.

Keywords: Natural orifice specimen extraction (NOSE); quality of life (QoL); colorectal cancer; laparoscopy; clinical efficacy

Submitted Dec 10, 2019. Accepted for publication Feb 26, 2020.

doi: 10.21037 /jgo.2020.03.05

View this article at: http://dx.doi.org/10.21037/jgo.2020.03.05 


\section{Introduction}

Laparoscopic surgery for colorectal cancer has been widely used for nearly 30 years (1). In comparison with open surgery (OS), laparoscopic surgery has shown advantages in surgical outcomes $(2,3)$. However, Conventional laparoscopic surgery requires the creation of a $5-10 \mathrm{~cm}$ abdominal wall incision for the removal of the intact specimen. More and more surgeons, to realize the greatest benefits of minimally invasive surgery, omitted this large abdominal extraction incision by using the technique of natural orifice specimen extraction (NOSE) (4).

Franklin was the first to report the NOSE during laparoscopic rectal and sigmoid resections in 1993 (4). In recent years, with the development of the NOSE technique and laparoscopic equipment, laparoscopic anterior resection with transrectal NOSE has become the preferred treatment for rectal cancer $(5,6)$. Difficulties in specimen extraction are often secondary to large tumors or obesity. NOSE has not been widely accepted because of the concerns of fecal contamination and malignant cell contamination of the pelvis (7). With the utilization of intrabdominal specimen sleeve pouch and intracorporeal placement of the stapler anvil this concerns may be alleviated (8-10).

Currently, no studies have been conducted to analyze the quality of life (QoL) of NOSE. Few studies explored the short term or long-term clinical efficacy, pain score and surgical complications with NOSE in sigmoid colon and rectal cancer $(11,12)$. Obtaining detailed data of NOSE surgery on the colorectal cancer patients is important because it can serve as the basis for identifying risk factors for impaired QoL. In this study, we assessed QoL and short-term recovery for rectal cancer between NOSE surgery, laparoscopy non-NOSE surgery, and OS.

\section{Methods}

\section{Research subjects}

We conducted a randomized prospective study of surgical procedures performed from April 2014 and February 2018 in Shanghai East Hospital. Patients were included if they were older than 18 years and had been diagnosed with middle and upper rectal cancer. The exclusion criteria were as follows: (I) preoperative examination confirmed with distant organ metastasis of tumors; (II) radiation therapy, chemotherapy, or immunotherapy was performed before surgery; (III) no complete clinical and pathological data; (IV) ulcerative colitis, Crohn's disease, or radiation proctitis in the intestinal canal distal to the tumor.

Participants were randomly assigned to the NOSE, nonNOSE and overall survival (OS) groups using a permuted block method. The randomization sequence was generated using a random number generating program, with a $1: 1: 1$ allocation ratio with blocks of different sizes to ensure a balanced allocation. Block sizes were randomly permuted. Electronic sequence generation and random allocation were performed centrally.

This study was approved by the Ethics Committee of the Shanghai East Hospital affiliated to Tongji University. This clinical study was registered on the Chinese Clinical Trial Registry (Registration number: ChiCTR1800014426, http://www.chictr.org.cn/index.aspx). Written informed consent was obtained from all patients.

\section{Surgical procedure}

The open/laparotomy was performed in a technically conventional approach (13). Colorectal resection was performed following the principles of total mesorectal excision (TME) tumor-specific mesorectal excision in all groups. Laparoscopy non-NOSE was performed technically as the NOSE procedure except the specimen was excised through the midline/periumbilical extraction site. The laparoscopic AR utilizing the transrectal NOSE was performed as followed. An umbilical tape was tied around the proximal of the rectum to prevent contamination of the pelvis with malignant cells or intestinal continents. The rectum/colon was then transected $1 \mathrm{~cm}$ distal to the lesion. Then the anus was dilated and the anvil of a $28 \mathrm{~mm}$ end to end stapler was placed in the pelvis through a protective sleeve pouch and was then placed in the left lower quadrant of the abdomen. Then a Kocker clamp was placed through the rectum while the specimen pouch was passed through an abdominal trocar, the specimen pouch was then brought through the anus and the specimen (rectum) was placed in the specimen pouch and extracted through the rectal. The rectal stump had a purse-string placed and the anvil was secured in the proximal colon an end to end anastomosis of colon and rectum was performed (Figure 1).

\section{Data collection}

The preoperative and postoperative clinical variables of the three groups of patients were recorded, including sex, 

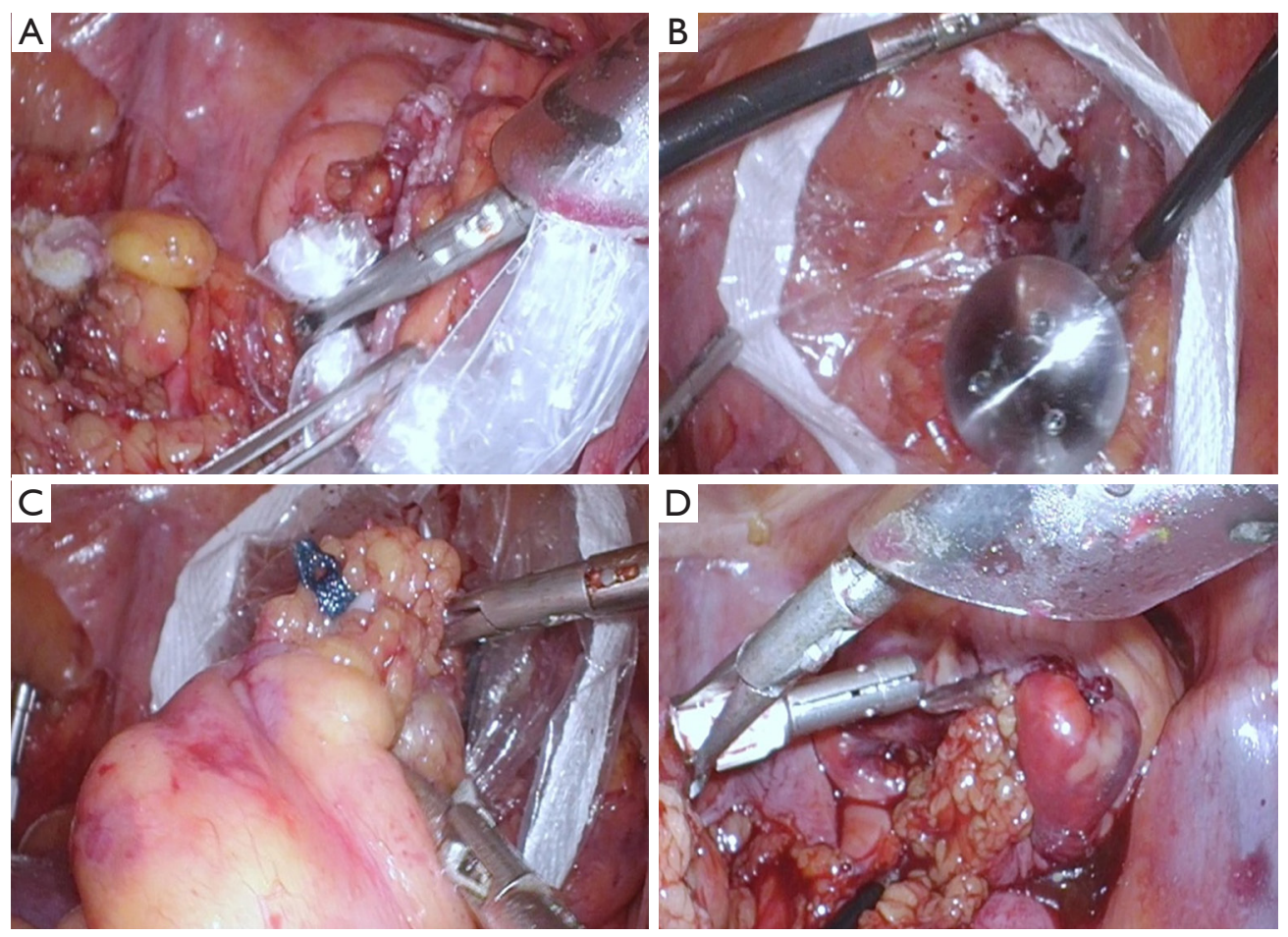

Figure 1 Surgical procedure for NOSE. (A) The specimen protective sleeve was inserted through the trocar, and a sterile channel was created; (B) staple anvil was inserted through the channel; (C) specimen was placed in the protective sleeve and pulled out; (D) the digestive tract reconstruction was finished in intra-abdominal operation.

age, BMI, tumor distance from the anal verge, history of previous abdominal surgery, and carcinoembryonic antigen (CEA) and carbohydrate antigen 19-9 (CA199) levels. The postoperative variables were including operation time, size of the tumor, intestine function recovery (flatus or stool), length of hospital stay, complications. The pathologist determined the integrity of the TME and the pathologic stage of rectal cancer. A 10-point visual simulation scale was used for the assessment of the level of pain. The VAS scores on the first and third postoperative days were collected by an experienced nurse and assessed in the three groups. A score of 0 indicated no pain, and a score of 10 indicated severe pain (14).

SF-36 questionnaire includes the following 8 items: physical functioning $(\mathrm{PF})$, role physical (RP), bodily pain (BP), general health $(\mathrm{GH})$, vitality $(\mathrm{VT})$, social functioning $(\mathrm{SF})$, role emotional (RE), and mental health $(\mathrm{MH})$. Each domain yields a score ranging from 0 to 100 , with higher values indicating better QoL (15). The patients enrolled in this study were invited to complete the SF-36 questionnaire for analysis in the first preoperative and sixth postoperative months. The SF-36 questionnaires were analyzed by an experienced doctor.

\section{Statistical analysis}

All data were completed by a professional teaching secretary, and the SPSS 20.0 statistical software was used for the data analysis. Measurement data were expressed as $(\bar{x} \pm S)$ and compared with the $t$-test, and the enumeration data were expressed as [n (\%)] and compared using a $\chi^{2}$ test. The scores on each item of the SF-36 scale in the three groups of patients were tested for homogeneity of variance using the Levene method. One-way analysis of variance was used for the comparison among the three groups, and the least significant difference $t$-test was used for further pairwise comparison. The survival curves were plotted with the Kaplan-Meier (K-M) method, and the log-rank test was used to analyze the relationship between the survival cycles of the two groups. Any difference with a $\mathrm{P}$ value of $<0.05$ 


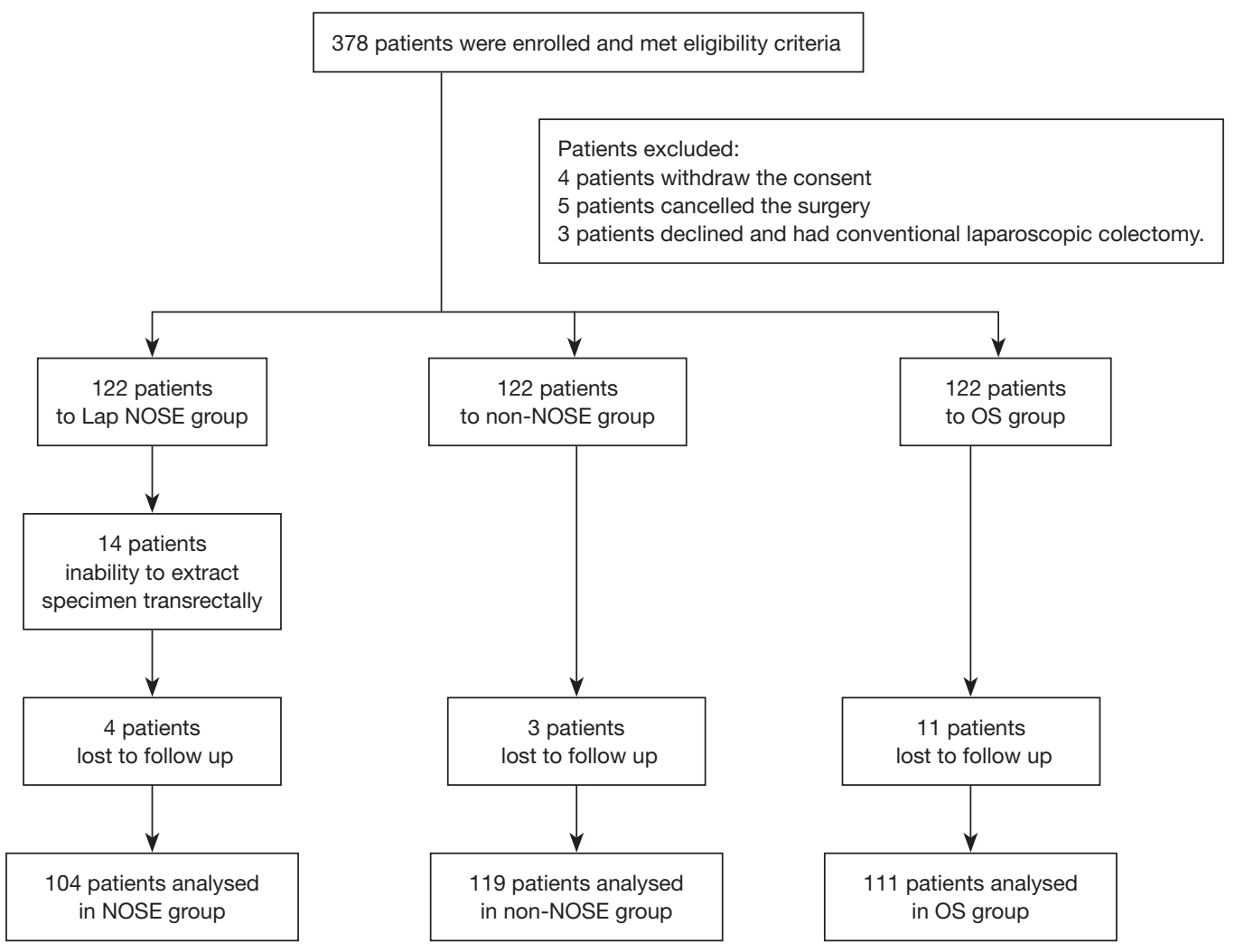

Figure 2 Study enrollment. NOSE, natural orifice specimen extraction; OS, open surgery.

was considered as statistically significant.

\section{Results}

A total of 378 patients were enrolled; 366 underwent randomization: 122 to each group; 14 patients in the NOSE group failed to extract specimens transrectally. Totally 18 patients were lost to follow up in three groups. Exclusions involved not proceeding to surgery or deviation from the study protocol (Figure 2). No statistically significant differences were found among the three groups in terms of preoperative indexes such as age, sex, BMI, tumor distance from the anal margin, and serum CEA and CA199 levels (Table 1).

\section{Clinical indexes among the three groups}

No significant differences in postoperative tumor diameter, lymph node positivity rate, and tumor staging were found among the three groups $(\mathrm{P}>0.05)$. When compared with the OS and non-NOSE groups $(97.9 \pm 37.3$ and $146.2 \pm 42.1 \mathrm{~min}$, respectively), the NOSE group had the longest operation time $(167.0 \pm 45.0 \mathrm{~min}, \mathrm{P}<0.05)$. The time of bowel function recovery were $16.0 \pm 6.0,25.4 \pm 6.2$, and $48.6 \pm 7.6 \mathrm{~h}$ in the NOSE, non-NOSE, and OS groups, respectively, with statistically significant differences $(\mathrm{P}<0.05)$. The mean lengths of hospital stay after surgery was $7.4 \pm 2.2$, $10.5 \pm 3.5$, and $12.3 \pm 4.2$ days in the NOSE, non-NOSE, and OS groups, respectively, with the differences achieving statistical significance $(\mathrm{P}<0.05)$. The incidence of postoperative complications in the OS group (29/111, $26.1 \%$ ) was significantly higher than the other two groups $(\mathrm{P}<0.05)$. The incidence of postoperative complications was lower in the NOSE group $(12 / 104,11.5 \%)$ than in the non-NOSE group $(20 / 119,16.8 \%)$, the difference was statistically significant. The VAS scores for postoperative 3 days were significant difference between the three groups. NOSE group was significantly lower than that of the nonNOSE and OS group $(\mathrm{P}<0.001)$ (Table 2).

\section{Disease-free survival (DFS) curve in the three groups}

The patients in the three groups were followed up for 
Table 1 Patient and tumor characteristics for NOSE, non-NOSE and OS groups

\begin{tabular}{|c|c|c|c|c|}
\hline Patient and tumor characteristics & NOSE & non-NOSE & OS & $P$ value \\
\hline Sex, $n$ & & & & 0.65 \\
\hline Male & 50 & 65 & 56 & \\
\hline Female & 64 & 56 & 50 & \\
\hline Tumor height from anal verger, mean $\pm \mathrm{SD}, \mathrm{cm}$ & $11.1 \pm 8.3$ & $13.0 \pm 11.1$ & $10.5 \pm 8.9$ & 0.19 \\
\hline Surgery history in abdomen, $\mathrm{n}$ & & & & 0.24 \\
\hline Yes & 10 & 6 & 13 & \\
\hline No & 104 & 115 & 93 & \\
\hline Abnormal & 43 & 52 & 38 & \\
\hline Preoperative CA-199, n & & & & 0.18 \\
\hline Normal & 90 & 90 & 87 & \\
\hline Abnormal & 24 & 31 & 19 & \\
\hline
\end{tabular}

NOSE, natural orifice specimen extraction; OS, open surgery; CEA, carcinoembryonic antigen; CA-199, carbohydrate antigen 19-9.

40 months. The K-M curve analysis in the three groups revealed no statistically significant difference in overall survival between the NOSE, non-NOSE and OS groups $(\mathrm{P}=0.815)$, (Figure 3).

\section{Assessment of QoL in the three groups of patients}

According to the SF-36 questionnaire, the mean scores in the preoperative QoL in the three groups (NOSE, non-NOSE, OS) were $94.6 \pm 2.7,95.5 \pm 2.4$, and $93.70 \pm 1.9$, respectively, with no statistically significant differences. During the sixth postoperative month, the NOSE and non-NOSE groups were superior to the OS group in terms of their scores in each item, with statistically significant differences. The NOSE group was superior to the group in the scores for $\mathrm{PF}, \mathrm{BP}, \mathrm{SF}$, and RE, with statistically significant differences. In the fields of physical health and MH, the NOSE group scored the highest, with statistically significant differences between the other two groups (Table 3).

\section{Discussion}

With the development of surgical techniques and equipment, the surgical treatment of colorectal cancer is gradually steering toward minimally invasive surgery, which is the current general trend in the field of surgery (16-18). Conventional laparoscopic requires the creation of a $5-10 \mathrm{~cm}$ abdominal incision for the removal of the intact specimen. Several surgeons, to realize the greatest benefits of minimally invasive surgery, omitted this large abdominal extraction incision by using the open rectum through which to remove the colonic specimen. This technique has come to be termed NOSE $(19,20)$. This study compared the clinical efficacy of NOSE, non-NOSE, and OS for colorectal cancer patients' short-term recovery and QoL.

NOSE is effective in reducing patients' postoperative pain by avoiding an abdominal extraction site (21). The relief of postoperative pain contributed to the rapid rehabilitation of patients (22). In this study, the postoperative VAS score in the NOSE group was lower than those in the other two groups. Besides, reducing the size of the abdominal incision is beneficial for the prevention of wound infection (23). This study shows NOSE was significantly superior to nonNOSE and OS in terms of the time for bowel function recovery, length of hospital stay, and other indexes. Also, postoperative complications were well controlled in the NOSE than non-NOSE groups. By avoiding an abdominal extraction site, NOSE can significantly improve patients' 
Table 2 Postoperative clinical indexes among the three groups (NOSE, non-NOSE, OS)

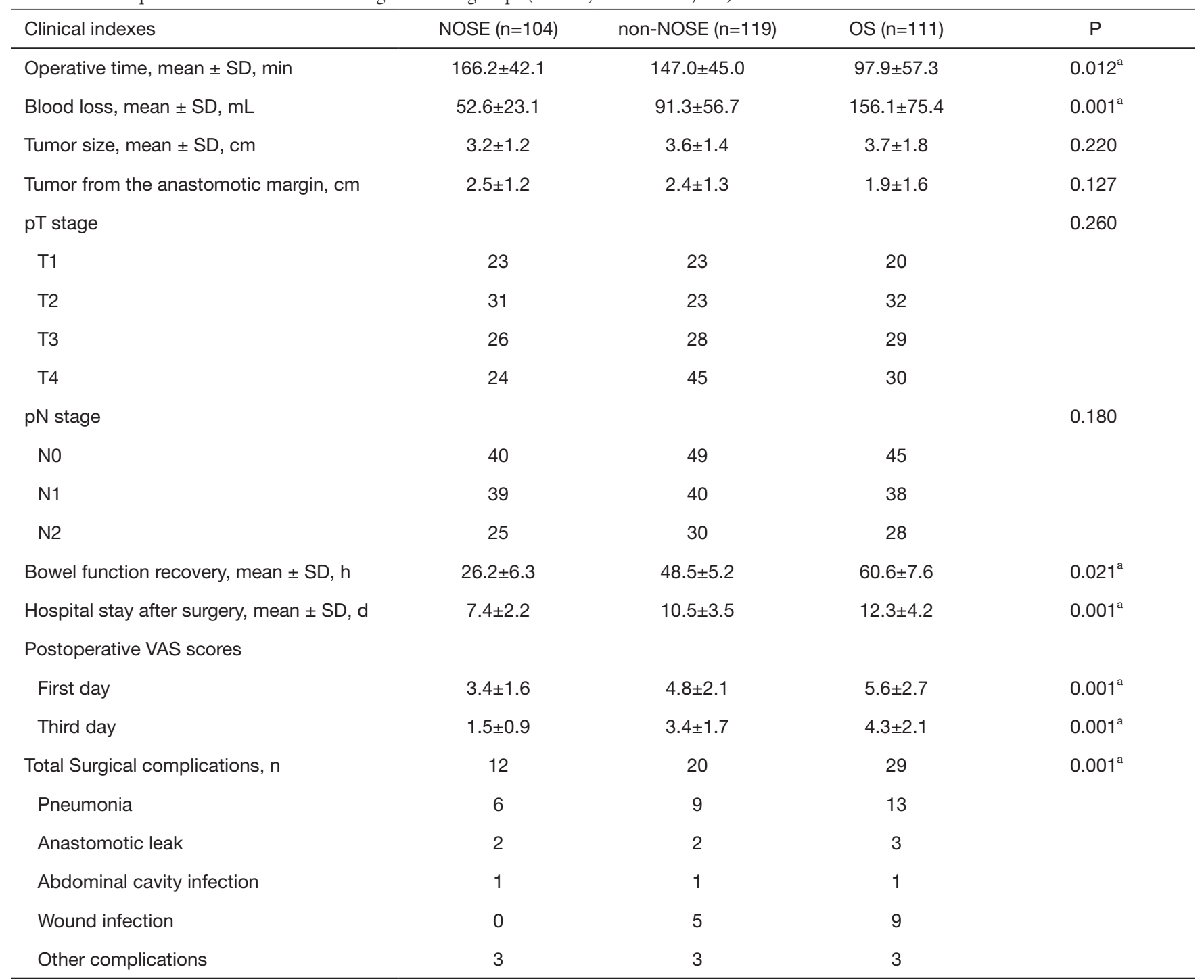

${ }^{a}$, the scores in three groups were tested for homogeneity of variance using the Levene method, $\mathrm{P}<0.05$. NOSE, natural orifice specimen extraction; OS, open surgery.

postoperative QoL while ensuring its clinical efficacy. This study shows significant differences in the patients' QoL in the sixth postoperative month among the three groups. The overall QoL was highest in the NOSE group and lowest in the OS group. Improved QoL enables patients with colorectal cancer to achieve better rehabilitation, thereby improving the quality of treatment and meeting the trend of minimally invasive surgery (24-26).

Our experience for transrectal NOSE surgery has three key surgical steps. The NOSE surgery for cancer must be completed in '1-out and 2-in'. Here, '1-out' refers to the removal of the specimen with protection sleeve, and '2in' refers to the insertion of the anvil into the abdominal cavity and placement in the proximal colon. In the previous study, a specimen protection sleeve was used, which provided an excellent solution for the problems associated with specimen removal and anvil introduction into the abdominal cavity (8). Instead of using the anus and rectum as the route of insertion, this study inserted the protection sleeve through the $12-\mathrm{mm}$ trocar in the abdomen, then pulled it out from the rectum in an anterograde fashion. The specimen was pulled out through the protection sleeve 
thus avoiding the risk of intra-abdominal contamination by tumor cells. A variety of methods have been reported for the placement of the stapler anvil in the proximal colon, which has shortcomings in terms of complicated use or implausible techniques $(27,28)$. The introduction of the central rod of the anvil into the sterile abdominal cavity from the non-sterile intestinal canal leads to a high risk of abdominal cavity contamination and violates the principle of a sterile operation. In the present study, we inserted the

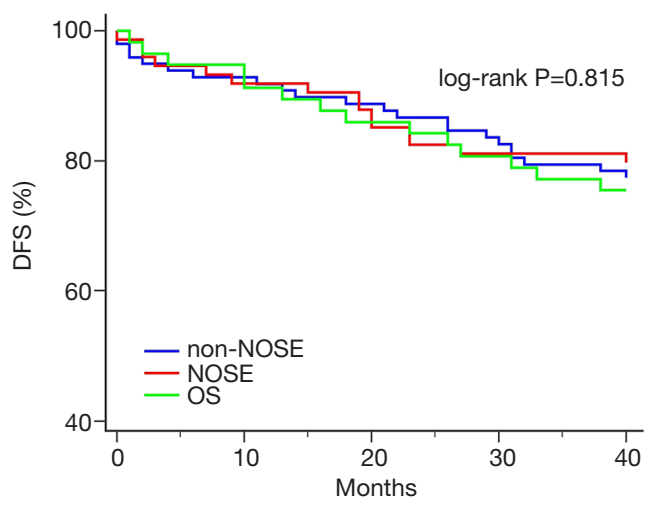

Figure 3 DFS between three groups. NOSE, natural orifice specimen extraction; OS, open surgery; DFS, disease-free survival. anvil into the proximal colon in an anterograde fashion, and subsequently ligated and fixed the anvil with a snare. These three steps were sure to avoid bacterial contamination and tumor cell shedding in the abdominal cavity during NOSE surgery.

The factors related to the difficulties of specimen extraction via NOSE were not analyzed in this study. Subsequent research will examine cases of NOSE-related specimen extraction failures and focus on parameters such as rectal diameter, mesorectal thickness, maximum tumor diameter, and tumor volume to identify groups that are eligible for NOSE surgery. Besides, as the sample size of this study was limited and a single-center clinical study was adopted, a multicenter randomized controlled study with large sample size is still needed to further clarify the clinical efficacy of NOSE.

In the area of minimally invasive surgery, the principle of surgery is to preserve as many normal tissues and organs as possible and reduce trauma and the impact on patient QoL under the premise of ensuring a safe and complete resection of lesions $(29,30)$. NOSE adheres to the concept of minimally invasive treatment and has an important value in the clinical promotion. However, as NOSE is still in the process of continuous development, surgeons must strictly grasp the indications so that patients can experience the real

Table $3 \mathrm{QoL}$ in the three groups of patients (points)

\begin{tabular}{|c|c|c|c|c|}
\hline The SF-36 survey, mean \pm SD & NOSE & non-NOSE & os & $P$ value \\
\hline PF & $91.7 \pm 8.2^{\mathrm{ab}}$ & $75.1 \pm 8.9^{\mathrm{a}}$ & $55.4 \pm 7.2$ & 0.000 \\
\hline $\mathrm{RP}$ & $75.4 \pm 9.1^{\mathrm{a}}$ & $70.8 \pm 8.6^{\mathrm{a}}$ & $42.2 \pm 6.1$ & 0.000 \\
\hline $\mathrm{BP}$ & $92.1 \pm 1.2^{\mathrm{ab}}$ & $71.3 \pm 7.7$ & $68.8 \pm 5.2$ & 0.005 \\
\hline Physical health domain & $83.4 \pm 7.8^{\mathrm{ab}}$ & $71.5 \pm 7.2^{\mathrm{a}}$ & $58.2 \pm 6.3$ & 0.000 \\
\hline \multicolumn{5}{|l|}{ MCS } \\
\hline VT & $71.9 \pm 6.2^{\mathrm{a}}$ & $70.6 \pm 9.5^{a}$ & $40.5 \pm 9.4$ & 0.001 \\
\hline SF & $92.2 \pm 5.5^{\mathrm{ab}}$ & $73.4 \pm 9.2^{\mathrm{a}}$ & $63.5 \pm 9.9$ & 0.003 \\
\hline MH domain & $78.8 \pm 7.8^{\mathrm{ab}}$ & $66.7 \pm 6.9$ & $47.3 \pm 8.3$ & 0.000 \\
\hline
\end{tabular}

a , compared with OS, $\mathrm{P}<0.05$; $^{\mathrm{b}}$, compared with Lap non-NOSE, $\mathrm{P}<0.05$. SF-36, Medical Outcomes Study Short Form-36. NOSE, natural orifice specimen extraction; OS, open surgery; PCS, physical component summary; MCS, mental component summary; PF, physical function; RP, role physical; BP, bodily pain; GH, general health; VT, vitality; SF, social function; EM, emotional performance; MH, mental health; QoL, quality of life. 
benefits of NOSE.

\section{Conclusions}

NOSE is associated with relatively low surgical compliance and better QoL at 6 months. With our method for NOSE, the oncological safety can be sure for colorectal cancer. NOSE is safe and is associated with good clinical efficacy.

\section{Acknowledgments}

Funding: This study was funded by the National Natural Science Foundation of China (81573004; 81773275; 81871953), the Health and Family Planning Committee of Pudong New Area (CN) (PWZzk2017-26, PWYgf2018-04) and the Science and Technology Commission of Shanghai Municipality (19411966500).

\section{Footnote}

Conflicts of Interest: All authors have completed the ICMJE uniform disclosure form (available at http://dx.doi. org/10.21037/jgo.2020.03.05). The authors have no conflicts of interest to declare.

Ethical Statement: The authors are accountable for all aspects of the work in ensuring that questions related to the accuracy or integrity of any part of the work are appropriately investigated and resolved. This study was approved by the Ethics Committee of the Shanghai East Hospital affiliated to Tongji University (No. SHSDFYY-2015-098). Written informed consent was obtained from all patients.

Open Access Statement: This is an Open Access article distributed in accordance with the Creative Commons Attribution-NonCommercial-NoDerivs 4.0 International License (CC BY-NC-ND 4.0), which permits the noncommercial replication and distribution of the article with the strict proviso that no changes or edits are made and the original work is properly cited (including links to both the formal publication through the relevant DOI and the license). See: https://creativecommons.org/licenses/by-ncnd/4.0/.

\section{References}

1. Clinical Outcomes of Surgical Therapy Study
Group, Nelson H, Sargent DJ, et al. A comparison of laparoscopically assisted and open colectomy for colon cancer. N Engl J Med 2004;350:2050-9.

2. Lacy AM, Delgado S, Castells A, et al. The long-term results of a randomized clinical trial of laparoscopyassisted versus open surgery for colon cancer. Ann Surg 2008;248:1-7.

3. Kennedy GD, Heise C, Rajamanickam V, et al. Laparoscopy decreases postoperative complication rates after abdominal colectomy: results from the national surgical quality improvement program. Ann Surg 2009;249:596-601.

4. Franklin ME Jr, Ramos R, Rosenthal D, et al. Laparoscopic colonic procedures. World J Surg 1993;17:51-6.

5. Cheung HY, Leung AL, Chung CC, et al. Endolaparoscopic colectomy without mini-laparotomy for leftsided colonic tumors. World J Surg 2009;33:1287-91.

6. Akamatsu H, Omori T, Oyama T, et al. Totally laparoscopic sigmoid colectomy: a simple and safe technique for intracorporeal anastomosis. Surg Endosc 2009;23:2605-9.

7. Senft JD, Droscher T, Gath P, et al. Inflammatory response and peritoneal contamination after transrectal natural orifice specimen extraction (NOSE) versus mini-laparotomy: a porcine in vivo study. Surg Endosc 2018;32:1336-43.

8. Wolthuis AM, De Buck Van Overstraeten A, et al. Laparoscopic NOSE colectomy with a camera sleeve: a technique in evolution. Colorectal Dis 2015;17:O123-5.

9. Wolthuis AM, Penninckx F, D'Hoore A. Laparoscopic sigmoid resection with transrectal specimen extraction has a good short-term outcome. Surg Endosc 2011;25:2034-8.

10. Wolthuis AM, Van Geluwe B, Fieuws S, et al. Laparoscopic sigmoid resection with transrectal specimen extraction: a systematic review. Colorectal Dis 2012;14:1183-8.

11. Xingmao Z, Haitao Z, Jianwei L, et al. Totally laparoscopic resection with natural orifice specimen extraction (NOSE) has more advantages comparing with laparoscopic-assisted resection for selected patients with sigmoid colon or rectal cancer. Int J Colorectal Dis 2014;29:1119-24.

12. Ma B, Huang XZ, Gao P, et al. Laparoscopic resection with natural orifice specimen extraction versus conventional laparoscopy for colorectal disease: a metaanalysis. Int J Colorectal Dis 2015;30:1479-88.

13. Keller DS, Tahilramani RN, Flores-Gonzalez JR, et al. Transanal minimally invasive surgery: review of indications and outcomes from 75 consecutive patients. J Am Coll Surg 2016;222:814-22. 
14. Bousquet PJ, Combescure C, Klossek JM, et al. Change in visual analog scale score in a pragmatic randomized cluster trial of allergic rhinitis. J Allergy Clin Immunol 2009;123:1349-54.

15. Apolone G, Filiberti A, Cifani S, et al. Evaluation of the EORTC QLQ-C30 questionnaire: a comparison with SF-36 Health Survey in a cohort of Italian long-survival cancer patients. Ann Oncol 1998;9:549-57.

16. Lorenzon L, La Torre M, Ziparo V, et al. Evidence based medicine and surgical approaches for colon cancer: evidences, benefits and limitations of the laparoscopic vs open resection. World J Gastroenterol 2014;20:3680-92.

17. Lee SH, Lim S, Kim JH, et al. Robotic versus conventional laparoscopic surgery for rectal cancer: systematic review and meta-analysis. Ann Surg Treat Res 2015;89:190-201.

18. Shida D, Ochiai H, Tsukamoto S, et al. Long-term outcomes of laparoscopic versus open D3 dissection for stage II/III colon cancer: results of propensity score analyses. Eur J Surg Oncol 2018;44:1025-30.

19. Palanivelu C, Rangarajan M, Jategaonkar PA, et al. An innovative technique for colorectal specimen retrieval: a new era of "natural orifice specimen extraction" (N.O.S.E). Dis Colon Rectum 2008;51:1120-4.

20. Fu CG, Gao XH, Wang H, et al. Treatment for early ultralow rectal cancer: pull-through intersphincteric stapled transection and anastomosis (PISTA) versus low anterior resection. Tech Coloproctol 2013;17:283-91.

21. Pedrazzani C, Menestrina N, Moro M, et al. Local wound infiltration plus transversus abdominis plane (TAP) block versus local wound infiltration in laparoscopic colorectal surgery and ERAS program. Surg Endosc 2016;30:5117-25.

22. Yamamoto M, Asakuma M, Tanaka K, et al. Clinical impact of single-incision laparoscopic right hemicolectomy with intracorporeal resection for advanced colon cancer: propensity score matching analysis. Surg Endosc 2019;33:3616-22.

23. Hisada M, Katsumata K, Ishizaki T, et al. Complete laparoscopic resection of the rectum using natural orifice specimen extraction. World J Gastroenterol 2014;20:16707-13.

24. Veltcamp Helbach M, Koedam TWA, Knol JJ, et al. Quality of life after rectal cancer surgery: differences between laparoscopic and transanal total mesorectal excision. Surg Endosc 2019;33:79-87.

25. Downing A, Glaser AW, Finan PJ, et al. Functional outcomes and health-related quality of life after curative treatment for rectal cancer: a population-level study in England. Int J Radiat Oncol Biol Phys 2019;103:1132-42.

26. DeCosse JJ, Cennerazzo WJ. Quality-of-life management of patients with colorectal cancer. CA Cancer J Clin 1997;47:198-206.

27. Christoforidis D, Clerc D, Demartines N. Transrectal specimen extraction after laparoscopic left colectomy: a case-matched study. Colorectal Dis 2013;15:347-53.

28. Nishimura A, Kawahara M, Suda K, et al. Totally laparoscopic sigmoid colectomy with transanal specimen extraction. Surg Endosc 2011;25:3459-63.

29. Forsmo HM, Pfeffer F, Rasdal A, et al. Pre- and postoperative stoma education and guidance within an enhanced recovery after surgery (ERAS) programme reduces length of hospital stay in colorectal surgery. Int J Surg 2016;36:121-6.

30. Keller DS, McGee MF, Goyal S, et al. Construct validation and comparison of a novel postoperative qualityof-life metric and the Short Form-36 in colorectal surgery patients. Surgery 2013;154:690-5; discussion 695-6.
Cite this article as: Zhu Z, Wang KJ, Orangio GR, Han JY, Lu B, Zhou ZQ, Gao W, Fu CG. Clinical efficacy and quality of life after transrectal natural orifice specimen extraction for the treatment of middle and upper rectal cancer. J Gastrointest Oncol 2020;11(2):260-268. doi: 10.21037/jgo.2020.03.05 